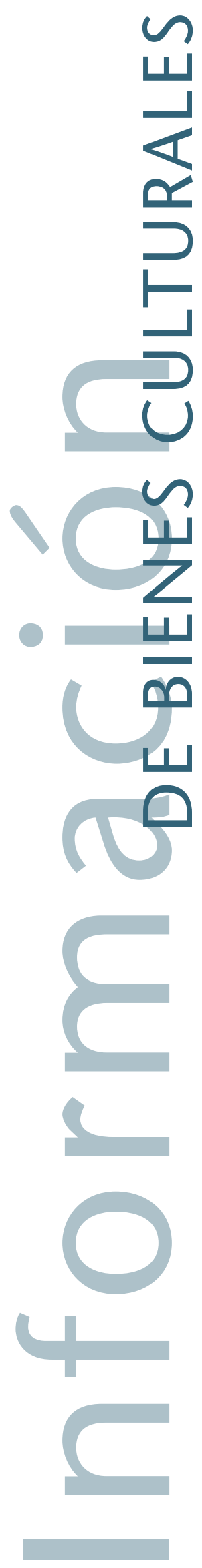

\title{
Informatización de la Planimetría de los inmuebles BIC de Sevilla incluidos en el archivo histórico de la Fundación FIDAS
}

\author{
Javier Lobato Domínguez \\ Carmen Frauca Belloso \\ Antonio Aceme Dávila
}

Centro de Documentación del IAPH

La realización de un proyecto conjunto entre el Instituto Andaluz de Patrimonio Histórico (IAPH) y la Fundación para la Investigación y Difusión de la Arquitectura. Sevilla (FIDAS) con el objetivo de documentar gráficamente las intervenciones realizadas durante los últimos 50 años sobre el patrimonio inmueble protegido de la provincia de Sevilla, supone una primera experiencia en la utilización de las fuentes archivísticas de los colegios profesionales de arquitectos como material de gran interés informativo, no solo para la gestión administrativa de la institución colegial, sino en su dimensión cultural y patrimonial. Consideramos este trabajo por tanto como un primer paso hacia una valoración por parte de las administraciones públicas de un Archivo, el del Colegio de Arquitectos de Sevilla, que por su volumen, alcance geográfico, y continuidad, es esencial para el estudio documentado de la Arquitectura de nuestra Comunidad.

El Colegio Oficial de Arquitectos de Sevilla conserva como uno de sus más preciados bienes patrimoniales su Archivo Histórico, hoy gestionado desde la Fundación FIDAS. En él se recoge documentalmente la historia de la institución y las funciones de control y difusión de la Arquitectura que desde sus orígenes tuvo encomendadas. Algunas series (actas de Juntas de gobierno, elecciones, correspondencia, libros registro de visado, etc.), parten de la fecha de fundación del Colegio de Andalucía, Marruecos y Canarias en 1931, y su entonces llamada Delegación de Sevilla, otras se inician en fechas algo más tardías, entre estas se debe destacar la serie de Trabajos Profesionales Visados, la mayor con diferencia del Archivo, en la que se conservan los expedientes que recogen la actividad profesional de los arquitectos en la provincia y ciudad de SeviIla desde 1949 hasta hoy. En ella por tanto se encuentra la documentación íntegra de todos los pro- yectos (nuevas plantas, reformas, restauraciones, rehabilitaciones, informes, etc.) que obligatoriamente debían ser visados por la institución colegial. Su interés documental es por tanto muy alto, tanto como fuente histórica como por su información técnica, ya que se puede seguir la evolución de la arquitectura desarrollada en nuestra tierra en los últimos 50 años. Y no sólo la de nueva planta, sino también en las intervenciones de reforma, restauración o rehabilitación sobre nuestro más valioso patrimonio inmueble, aquellos monumentos histórico-artísticos hoy protegidos como Bienes de Interés Cultural. En estos proyectos se documentan perfectamente el alcance y criterios de la intervención y en ocasiones se analiza el edificio tanto en lo puramente constructivo (materiales, técnicas, patologías) como en sus facetas histórica y funcional aportando valiosa información sobre el mismo.

No es este el único aspecto de interés patrimonial del Archivo Histórico de FIDAS ya que además de la documentación propia de la Institución se han incorporado Archivos privados de arquitectos que completan con sus memorias, bocetos y planos, la información del quehacer de algunos de nuestros más importantes arquitectos (Anibal González, Díaz Langa, hermanos Barquín y Barón, Aguilar) y en ocasiones contienen información de cronología anterior (principios de siglo Archivo Anibal González) o referida a un ámbito geográfico más amplio (toda Andalucía Archivo de Aguilar).

Conocido este patrimonio documental por el Instituto Andaluz del Patrimonio Histórico por las relaciones mantenidas con la fundación. El 23 de junio de 1997 se solicita por parte de la Fundación FIDAS representada por su presidente D. Pedro Pablo Gómez Barañano una subvención a la Consejería de Cultura por medio del Instituto Andaluz del Patrimonio Histórico. Con el objetivo de desarrollar un proyecto en común entre ambas instituciones, proyecto que inicialmente se tituló : "Informatización de la documentación planimétrica del Archivo Histórico de la Demarcación de Sevilla del COAAOc relativa a los inmuebles incluidos en la relación de Bienes de interés cultural en la Provincia de Sevilla". Subvención que fue concedida el 25 de septiembre de 1997. 
La tarea inicial fue realizar un muestreo de la documentación existente relativa a la lista inicial de los 380 inmuebles protegidos de la provincia de Sevilla y un estudio detallado de los costes de realización del proyecto. Con ello conseguimos evaluar el volumen aproximado de expedientes sobre intervenciones en inmuebles declarados $\mathrm{BIC}$ o que contaran con otras categorías de protección y una estimación de los costes de las diferentes etapas del trabajo: documentación (localización y consulta de datos y expedientes), creación de la base de datos, carga de información en la misma, escaneo de planos, elaboración de informes y memorias, pudiendo así valorar la cantidad de documentos a tratar. Con esta información acordamos entre ambas instituciones limitar esta primera fase del proyecto al municipio de Sevilla ( 170 edificios) y a los bienes declarados BIC del mismo, lo que daba un total de 90 inmuebles o conjuntos con el máximo grado de protección otorgado por la Junta de Andalucía, sobre los que planteamos inicialmente seleccionar 500 planos para su tratamiento informático.

\section{Fases de la documentación}

La fase de documentación parte del listado de los 90 $\mathrm{BIC}$ seleccionados, de los que el IAPH facilitó una serie de datos identificativos, y se estructuró en sucesivas etapas que, a su vez, comprendían diversos trabajos :

I. Búsqueda de la información en los diferentes instrumentos de descripción del Archivo.

a) Fichas de Control de la Sección Trabajos Profesionales Visados. (1932-1997)

- Fichas topográficas.

- Fichas de trabajo por colegiados.

b) Base de datos de Trabajos Profesionales Visados (1986-1998)

c) Inventarios del Archivo. (Administrativo e Histórico)

2. Localización física de los expedientes en los respectivos depósitos del archivo, tanto del administrativo como del histórico.

3. Análisis y toma de datos de cada una de las unidades archivísticas (Expedientes).

Pasaremos a describir más detalladamente cada una de las etapas anteriormente mencionadas.

\section{Búsqueda de la información}

El acceso a la información de las intervenciones acometidas en cada uno de los edificios se realizó partiendo de los instrumentos de descripción disponibles, que en un archivo como el nuestro con más de 30.000 cajas y 300.000 expedientes y que abarcan una cronología de 67 años (1932-1998) son varios y en distintos soportes físicos: Inventarios en papel, ficheros alfabéticos, y catálogos en bases de datos (1986-1998).

a) Fichas de Control de la Sección Trabajos Profesionales Visados (1932-1997)
Esta serie del archivo está constituida por dos grupos de ficheros alfabéticos en los que se organiza la información sobre los expedientes visados: topográfico (municipio, calle, etc.) y de colegiados (trabajos ordenados cronológicamente de cada arquitecto). Son medios de información imprescindibles para la localización de los expedientes, que todavía no han sido informatizados.

El fichero topográfico con unas 230.000 unidades se divide en tres secuencias cronológicas cada una manteniendo el orden interno alfabético, son las siguientes:

$\begin{array}{ll}1^{\mathrm{a}} & 1932-1973 \\ 2^{\mathrm{a}} & 1973-1980 \\ 3^{\mathrm{a}} & 1980-1997\end{array}$

La información que se detalla en cada ficha es: ubicación del edificio (localidad, calle y número) nombre del propietario o persona/institución que encarga la obra, arquitecto/s que la proyectan y dirigen, breve reseña del tipo de intervención (reforma, nueva planta, etc.), la fecha del encargo y, sobre todo, el número de expediente, elemento clave para la localización posterior del mismo en el Inventario del archivo.

A estas Fichas se puede acceder según diferentes palabras-clave o voces que indican normalmente la localidad y calles, ante la inexistencia de un índice de control o tesauro (estamos hablando de 1932). que controlase la introducción de las fichas o su actualización los problemas de recuperación son evidentes: duplicidades de entradas para términos poco precisos, elección aleatoria del término que alfabetiza; a lo que debemos añadir que al tratarse de edificios (que en ocasiones dan a varias vías públicas), los nombres y números de calles e incluso de sectores urbanos de nueva urbanización presentan numerosos cambios en el nomenclator y númeración, cuando no se recurre a la utilización de claves identificativas provisionales (números de polígonos, manzanas o calles) y, ocasionalmente, cuando son edificios singulares se alfabetizan mediante los términos que indican la tipología o nombre del edificio, con todas sus variantes funcionales y cronológicas (Conventos, Pabellones de las exposiciones de 1929 y 1992, Museos, Plaza de toros, Universidad, etc.). Toda esta casuística dificulta la tarea de recuperar la información.

Este hecho obliga a rastrear todas las posibles voces o variantes con que se conozca una vía pública, o edificio en los ficheros topográficos, labor que ralentiza el proceso de búsqueda. Ya que un BIC como el monasterio de San Clemente puede aparecer indizado por los términos c/ Reposo n 9. c/ Santa Clara n 91 c/ Torneo, s/n., c/ Blanquillo s/n, San Clemente, iglesia, monasterio o convento de San Clemente o Pabellón de Sevilla en la Exposición Universal de 1992. Este ejemplo, afortunadamente no muy frecuente, indica la necesidad de generar un índice o tesauro de esta serie que organice jerárquicamente las palabras y frases, actualizando aquellos términos imprecisos y unificando criterios.

El fichero alfabético de trabajos visados por colegiados complementa la información ofrecida por el topográfi- 
co y presenta menos problemática en la elección de términos (apellidos y nombre del arquitecto).

Es un fichero que engloba todas las obras encargadas y dirigidas por todos y cada uno de los Arquitectos colegiados. El fichero lo componen tres grupos de fichas diferenciados por un criterio cronológico.

Es una fuente de información de gran utilidad por los datos que en ella se recogen. El criterio de ordenación de las fichas es el alfabético por el apellido de los arquitectos. Se abre una ficha para cada una de las intervenciones que se le encargan, que se ordenan a su vez cronológicamente. La información más valiosa que aportan es que en ellas se reflejan todos los documentos que la obra genera y su fecha (Proyecto básico, de ejecución, reformados, etc.), constituyendo casi una ficha catalográfica del expediente. El único inconveniente que existe es que comienzan a cumplimentarse a finales de los años 60 faltando información para las dos primeras décadas de expedientes visados del archivo. Este inconveniente fue en parte solventado con la consulta de otra serie documental los Documentos de encargo.

\section{b) Documentos de encargo}

Documento de control en el que se recogen los encargos de trabajo por colegiados. La serie comienza en 1932 y ofrece menos información que las fichas de control anteriores pero en ocasiones es el único instrumento de localización disponible. Valorando su interés, limitamos su uso a los referidos a aquellos arquitectos que por cargo o especialización habían tenido especial responsabilidad en obras de restauración o rehabilitación de edificios históricos $(\mathrm{BIC})$ : arquitecto diocesano, maestro mayor de la catedral, conservador del Alcázar, etc.

\section{c) Base de Datos de Visado}

La última forma de localización de expedientes es a través de la Base de Datos de Visado del Colegio. Importante medio de información que recoge con carácter exhaustivo todos los datos documentales y de tramitación de los expedientes visados.

La ventaja de esta fuente es que la información se recupera con rapidez desde cualquiera de los campos (indexados) en que se estructura la base de datos. El único problema que presenta es su limitación cronológica ya que sólo están incorporados los expedientes tramitados con posterioridad al año 1986, fecha en que se informatiza el trámite administrativo del visado. Nuestra actual base de datos nace en marzo de 1996, aunque trabaja con información importada de otra elaborada en Clipper, que aunque con menor volumen de información, si contiene la suficiente, como para poder afirmar con rotundidad que está actualizada desde mediados de 1986. Esta Base de Datos está mantenida mediante un programa desarrollado en lenguaje TSL4, lenguaje de $4^{\mathrm{a}}$ generación soportado bajo Sistema UNIX (HP9000), y basado en SQL.
El volumen de expedientes contenidos en la base de datos de visado es de 70.505 , mientras que los documentos, es decir, cada uno de los diferentes actos administrativos que generan documentación relativa de un expediente, asciende a 214.903 (enero 1999).

\section{Localización física de los expedientes en los respectivos depósitos, tanto del archivo administrativo como del histórico}

Finalizado el proceso de búsqueda de información sobre las intervenciones realizadas en cada uno de los BIC, era necesario proceder a la localización física de los expedientes en los depósitos y a su reagrupación en la sede del FIDAS.

Esta tarea, en principio mecánica, se complica relativamente al dividirse el archivo en dos: histórico y administrativo con diferente tratamiento en lo que afecta a la ubicación física de los fondos (diferente sistema de numeración de los expedientes y signaturado de las unidades de instalación), e instalación en depósitos diferentes y distanciados.

Así nos encontramos con que la localización de los expedientes más antiguos del archivo, custodiados en la sede del FIDAS (Archivo Histórico), no presenta ninguna problemática. A cada una de las intervenciones, que generan un expediente, se le asigna un número currens, dato que aparece recogido en las Fichas de Control de Trabajos Profesionales, y en el Inventario del archivo que, a su vez, nos remite a la unidad de instalación en la que se encuentra.

En el archivo administrativo los expedientes se organizan anualmente por fecha de visado y no por número corrido de expedientes, presentando las unidades de instalación signaturas provisionales. Por tanto para localizar un expediente es necesario conocer el número del mismo, que siempre aparece consignado en las fichas topográficas de control de los trabajos profesionales, y la fecha exacta de visado, dato este último que no es fijo en las mencionadas fichas y que obliga a buscar la ficha alfabética del arquitecto encargado de dirigir los trabajos técnicos para conocerla. Con ambos datos, fecha y número de expediente, se puede consultar el Inventario que nos indica la signatura provisional de la unidad de instalación en la que se conserva el expediente.

La casuística más problemática la plantean aquellos expedientes abiertos durante un largo periodo de tiempo, a veces incluso una década, y que presentan entradas variables de documentación, es decir, periodos en los que casi permanecen inactivos y otros en los que por cualquier circunstancia la intervención es impulsada y se genera un gran movimiento de entrada-salida de documentación que se organiza por la fecha de apertura del expediente.

Para facilitar el trabajo posterior fue conveniente reagrupar físicamente todos los expedientes localizados en un mismo lugar, la sede del FIDAS, creando una es- 
pecie de "sección facticia", que a la finalización del proyecto se disolverá con la reintegración de los expedientes a su lugar de origen.

Este hecho obligó al traslado de parte de la documentación desde el archivo administrativo, ubicado en la sede del Colegio, a la sede del FIDAS, en el Pabellón de Finlandia, y a la salida para consulta en sala de la documentación custodiada en FIDAS. Para la labor de préstamo entre ambos archivos era obligatorio cumplimentar una ficha de préstamo en el administrativo y otra de consulta en sala en el archivo histórico. Estas cautelas, hoja de préstamo y de consulta en sala, son necesarias para facilitar el control del movimiento de la documentación dentro de la propia institución (peticionario, asunto, fecha en la que hace la petición...) y para facilitar el reintegro de la documentación a su lugar de origen una vez finalizada la consulta.

\section{Análisis de cada una de las unidades archivísticas (expedientes), tanto simples cuando se trata de un documento solo como aquellos compuestos de varios documentos que no deben separarse porque corresponden a un mismo trámite administrativo (Proyecto) que siempre será respetado (orden natural de los documentos)}

Con el expediente de cada una de las intervenciones realizadas en un BIC a la vista, los datos extraídos de las Fichas de Control de Trabajos Profesionales, se procede a la revisión del expediente, su ordenación previa y lectura de la memoria del proyecto. Esta última labor aportó gran cantidad de información sobre el BIC, las intervenciones en él acometidas con anterioridad, su tipología, arquitecto/s que las dirigieron. Datos de interés para en muchos casos reiniciar la búsqueda de aquellas intervenciones que no hubiesen sido localizadas por los cauces descritos anteriormente.

Todas estas tareas ayudaban a clarificar el orden interno de los expedientes, los documentos que los componían y los planos que acompañaban a esos documentos.

Con las labores previas descritas se obtenía la información con la que se cumplimentaba la ficha-modelo de toma de datos diseñada en correspondencia con la Base de datos a la que finalmente volcaría toda su información. En ella se organizaban los datos en grupos de campos descriptivos (bloques o módulos) organizados jerárquicamente.

Cabecera (Datos básicos de identificación)

Este apartado incluye todos los datos identificativos del BIC, obtenidos de la Base de datos y a su vez de las tablas facilitadas por el IAPH que procedían de su base SIBIA

- Código: número de entrada-clave, notación única que identifica inequívocamente al registro.

- Categoría del BIC: con ella se indica a que grupo se adscribe el edificio según la clasificación establecida en la LPHA.
- Provincia y Municipio: por defecto la Base de Datos indica el término de Sevilla.

- Nombre del BIC: se indica el nombre del BIC de una forma normalizada.

- Emplazamiento: con indicación de la calle y el número

Intervenciones en el BIC

En este apartado se desciende a consignar los datos relativos a cada una de las intervenciones acometidas en el BIC. Los datos reseñados son los siguientes:

- Signatura+Fecha: es un número codificado de ocho dígitos distribuidos en dos grupos separados por una barra oblicua (/), el primer grupo de dos dígitos indica el año y el segundo el número de expediente. En caso de los expedientes cuyo número no indica el año o no es de seis dígitos la serie se completará con ceros.

- Año Comienzo: Indica el año en que se inicia la intervención. Este dato se suele tomar de la memoria.

- Año Fin: Indica el año en que se da por finalizada la intervención. Este dato se toma siempre del Certificado de Fin de Obra que deja constancia fidedigna de que la obra fue ejecutada. En caso de no conservarse el mismo (por no emitirse) este casillero se quedará en blanco, aunque se tenga constancia de la realización de la obra por otros medios.

- Tipo de intervención: Es una información importante porque da idea del alcance y finalidad de las obras. Es un dato que puede buscarse en el título de la intervención, lectura de la memoria del proyecto y fichas de arquitectos colegiados. Para elegir el término adecuado partimos de un índice de tipos de trabajo que existe como tabla informática en la base de datos de visado.

- Título: El título suele variar según la fuente de información que se consulte. Para salvar las diferencias en su enunciado se acordó tomarlo siempre de la memoria por ser el más completo y representativo.

- Promotor: Es una información fácil de averiguar ya que se repite en numerosos documentos del expediente y en las distintas fuentes de información.

- Descripción: Es una breve reseña del objeto y alcance de la intervención. La descripción pretende dar al usuario una visión completa de las obras proyectadas, de los criterios seguidos para realizarlas y evitar que prolongue la consulta si no es necesario. Es un apartado que obliga a una lectura atenta y detenida de la memoria y a su cotejo con lo reflejado en la planimetría aportada para dar una panorámica real de lo que la intervención supuso para el inmueble.

- Arquitecto/s: En este apartado se deja constancia de los arquitectos encargados de la autoría y dirección de los trabajos técnicos, independientemente del grado de responsabilidad que detentasen. Se indican tanto los arquitectos autores del proyecto como los directores de la obra, o los colaboradores que prestaron sus servicios en la obra. Nunca se reseñan otro tipo de profesionales (arquitectos técnicos, ingenieros, estudiantes...). El dato del arquitecto, por su importancia, es fácil de localizar en cualquiera de las fuentes consultadas. La normalización de nombre y apellidos venía dada por la tabla informática de la base de datos de visado. 


\section{Descripción del expediente}

En este nivel informativo se desciende a reflejar el orden secuencial de los documentos que conforman el expediente y se aportan unos datos mínimos pero de gran valor como son las fechas extremas de cada uno de los documentos y los planos que aportan cada uno de ellos. Este último dato obliga al recuento total de los planos, que si bien es una labor rutinaria, necesita de la revisión y ordenación previa de los mismos. El valor de este dato queda patente cuando se compara el número total de planos de cada intervención y el número de los planos seleccionados.

\section{Descripción de planos seleccionados}

El último nivel de descripción pretende dejar constancia gráfica del estado del edificio antes de la intervención y del estado del mismo tras llevarse la misma a cabo.

En los edificios que presentaban una intervención que se ejecutaba por fases se seleccionaban los planos del estado original del mismo y del estado final. En caso de que las intervenciones fuesen de distinta índole (consolidación, rehabilitación...) o afectasen a zonas diferentes del mismo edificio se dejaba constancia de cada una de las obras emprendidas.

Ante la variedad de la tipología de planos (planos generales de planta ya sean de cotas o de distribución, alzados y secciones, estructura, instalaciones, planos de detalles...) se seleccionaban los que fueran más representativos para el estudio general del edificio y que tuviesen buena calidad para su posterior escaneo.
Los planos escogidos fueron los de planta, secciones (longitudinales y transversales), fachadas (principal y laterales), demás alzados y, excepcionalmente, algunos planos de detalles (artesonado, solerías...) o que reflejaban las patologías que afectaban al edificio.

Los datos indicados de los planos son los precisos para identificarlo y conocer a que documento dentro del expediente pertenecen, el número, título exacto y escala/s. Todos ellos están bastante regularizados y suelen aparecer en la carátula dispuesta a tal efecto en los propios planos.

\section{Diseño de la base de datos: Tablas, Relaciones e informes}

El IAPH viene trabajando desde 1993 en una base de datos denominada (SIBIA), cuyo principal objetivo es la configuración de un Sistema de Información de los Bienes Inmuebles del Patrimonio Histórico Andaluz como instrumento de información básico para los procesos administrativos de tutela y difusión que el Instituto tiene encomendados. Adaptándonos a los criterios de normalización y compatibilidad de la información es por lo que al elaborar este proyecto se ha optado por la aplicación Microsoft Access'97 para el diseño de nuestra base de datos documental.

Partimos por tanto del sistema modular de la base de datos (SIBIA), de la que importamos las tablas de datos correspondiente a la identificación y situación legal de los bienes inmuebles seleccionados. Estas tablas

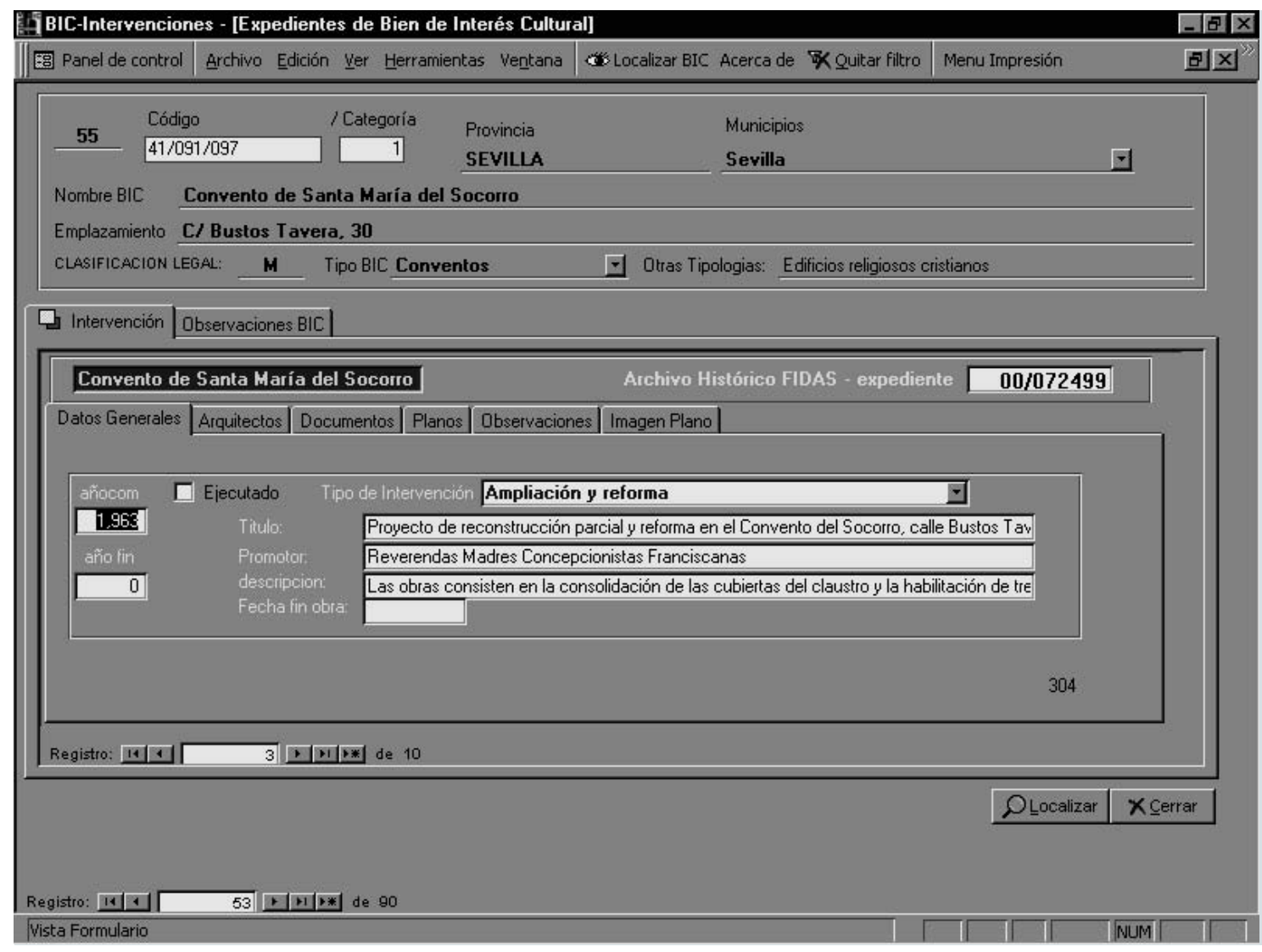


constituyen el primer módulo de nuestra aplicación, con ello ambas bases de datos pueden ser relacionadas y utilizadas conjuntamente (pantalla $n^{\circ} \mathrm{I}$ ). Al ser Access una herramienta ampliamente extendida y difundida, sus tablas o parte de ellas pueden ser exportadas y utilizadas por multitud de otras aplicaciones, presentando compatibilidad total con entorno Windows'95, Windows'98, Windows NT así como otros sistemas que utilicen ODBC (Open Database Connectivity). Facilitando su difusión en Internet mediante consultas dinámicas por ASP (Active Server Pages), ISAPI de IIS (Internet Information Server), SQL, etc.

El siguiente módulo (Intervenciones documentadas) que a su vez se subdivide en seis submódulos se diseñó con la finalidad de reunir de forma clara y precisa el máximo de información aportada por los expedientes de nuestro archivo sin necesidad de cambiar de pantalla para ello se opto por un sistema de visualización FRAME (ventanas emergentes a las que se accede desde la pantalla principal) (ver anexo pantalla $n^{\circ}$ I). Este modulo se relaciona con el primero por medio del código del BIC mediante Integridad Referencial, asume el nombre del BIC del modulo uno como cabecera identificativa del siguiente modulo y admite como entrada el número de expediente que será la relación principal para los siguientes submódulos, de este modo tenemos relacionado edificios con intervención.

Submódulo uno (Datos Generales) (Fig. I)

Se estructura en los siguientes campos:

Tipo de intervención: Campo desplegable cuya tabla inicial se importó de la base de datos de visado reduciéndola a los términos que consideramos más significativos. (Campo ComboBox alfanumérico con 35 dígitos)

Titulo: datos tomados del expediente. (Campo texto alfanumérico con 200 dígitos)

Promotor: datos tomados del expediente (Campo texto alfanumérico con 100 dígitos)

Descripción: resumen extractado del expediente (Campo texto alfanumérico con $65 \mathrm{~kb}$ )

Fecha fin obra: fecha del certificado final de obra cuando éste existe (Campo fecha con formato)

Ejecutado: campo predeterminado a vacío salvo que exista fin de obra. (Campo Bolean con I byte). Ver automatización.

Fecha inicio: (Campo numérico entero con formato)

Fecha fin: (Campo numérico entero con formato)

Submódulo dos (Arquitectos) (Fig. 2)

Apellidos y Nombres: Datos tomados de la tabla de Arquitectos colegiados de la Base de Datos de Visado actualizada con datos anteriores a 1986. (Campo alfanumérico relacional con tabla indexada con 47 dígitos)

Submódulo tres (Documentos) (Fig. 2)

Signatura del Expediente: Campo alfanumérico de 9 dígitos con toma de datos automática.
Número de documento: Indica cada uno de los actos documentales diferenciados. (Campo relacional mediante ComboBox con tabla indexada y con 7 dígitos)

Título del documento: (Campo relacional mediante ComboBox con tabla indexada y con 100 dígitos)

Fecha del documento: Tomado de la memoria del expediente siendo la formula mas frecuente la de mes $y$ año.(Campo alfanumérico con formato simulado de fecha de 8 dígitos

Fecha de visado: Tomado del sello de visado con formato día/mes/año. (Campo fecha con formato).

Número total de planos: Referidos a cada unidad documental. (Campo numérico simple con 4 dígitos.

Submódulo cuatro (Planos) (Fig. 2)

Signatura del Expediente: Campo alfanumérico de 9 dígitos con toma de datos automática.

Plano número: Indica un orden ascendente. (Campo alfanumérico con 10 dígitos)

Tipo de documento: Indica a que acto documental diferenciado pertenece. (Campo relacional mediante ComboBox modificable con tabla indexada y con 35 dígitos)

Número de plano: Según indica la carátula. (Campo numérico con 4 dígitos)

Título del plano: Según indica la carátula. (Campo alfanumérico con 200 dígitos)

Escala: Según indica la carátula. (Campo relacional mediante ComboBox con tabla indexada y con 4 dígitos numérico)

Plano seleccionado: Señala si el plano está escaneado y seleccionado para su entrega. (Campo SI/NO)

Observaciones: (Campo alfanumérico con 100 dígitos)

Submódulo cinco (Observaciones) (Fig. 2)

Observaciones: Las que se observen con carácter general relativas a la intervención. (Campo memo con 64 Kb)

Submódulo seis (Imagen Plano) (Fig. 2 y 3)

Repite de forma automática los campos del Módulo cuatro (Planos) incorporando imagen escaneada en formato reducido de aproximadamente $125 \times 55 \mathrm{~mm}$ y resolución aproximada de 96 ppp. Plano integrado en la propia base de datos que mediante el campo Nombre del Fichero Imagen permite la visualización del formato original en TIFF comprimido con resolución de $300 \times 300$ ppp. En blanco y negro.

La mayoría de las relaciones ente las tablas están definidas con exigencia de Integridad Referencial incluidas actualizaciones y eliminaciones en cascada. Hemos añadido tablas de colegiados y tipo de obra que pueden ser relacionadas con la base de datos de visado, al igual que los códigos/signaturas de expedientes.

El Colegio Oficial de Arquitectos de Sevilla, en su tarea de informatización del Archivo de Planeamiento, 
tiene larga experiencia en utilización de aplicaciones para la visualización rasterizada de planos. Tengamos en cuenta que la mayoría de los planos utilizados en la Base de Datos ahora creada por FIDAS para tratamiento de información textual y gráfica relativa a los BIC, tienen dimensiones de $2 \mathrm{mts} \times 1.5 \mathrm{mts}$ y tamaños digitales de entre $700 \mathrm{~Kb}$ y I Mb ya comprimidos, por tanto la utilización ágil y rápida de este fichero es problemática. Para ello en la Base de Datos $\mathrm{BIC}$ se decidió tener dos tipos de imágenes, por un lado la rasterizadas a escala normal que se almacenan en dispositivo aparte (ZIP, CDRom, otra unidad lógica, etc.) y, otras imágenes reducidas que son almacenadas en la propia la Base de Datos BIC. Con ello conseguimos disminuir ostensiblemente el tamaño de la Base de Datos y la agilización y eficacia de la misma.

\section{Evaluación de resultados:}

Una vez terminadas las fases de documentación y carga de datos en la base pudimos elaborar los primeros informes que daban un total de 389 intervenciones sobre 73 inmuebles declarados BIC con un total de 4642 planos de los que se seleccionaron 1 I I 8 para su escaneo.

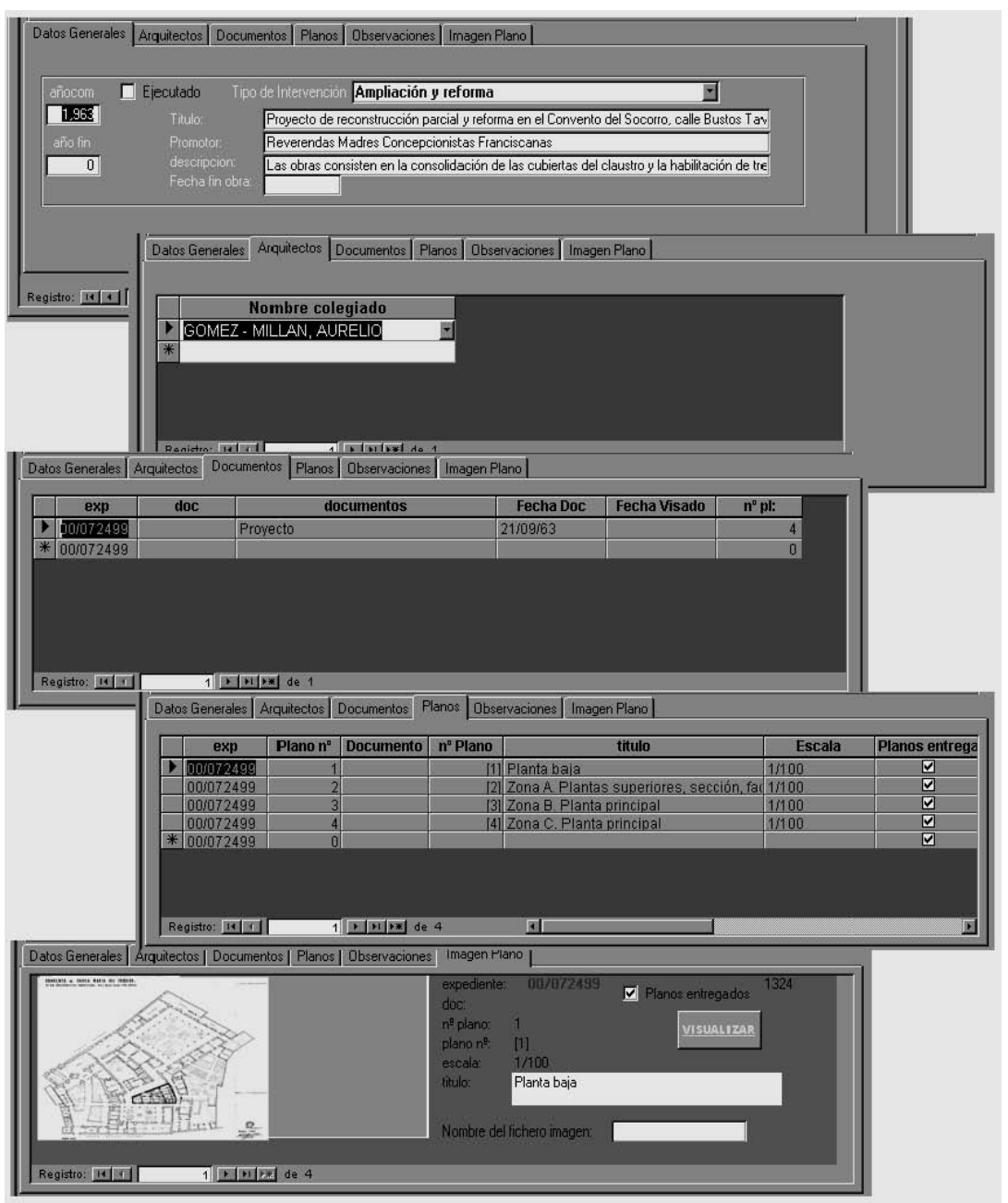

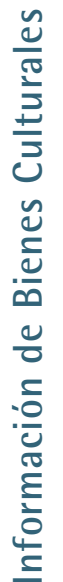

De los $90 \mathrm{BIC}$ seleccionados comprobamos que dos estaban duplicados quedando reducidos a 88 , de 15 de ellos (17\%) no encontramos ninguna documentación de los 73 restantes (83\%) existía alguna intervención documentada oscilando según los inmuebles entre I y 4 I expedientes localizados y descritos. De 65 edificios (74\%) se seleccionaron algunos planos significativos para su escaneo e incorporación a la base de datos variando también en número de planos seleccionados entre $\mid$ y $8 \mid$.

Estudiada la documentación se percibe que están mejor documentadas las obras e informes promovidos por particulares, sobre todo las de la Iglesia, y las de grandes casas o casas-palacios de propiedad privada, en general también están bien documentadas las realizaciones que se llevaron a cabo en inmuebles emblemáticos de la ciudad con motivo de la Exposición Universal de 1992 (Cartuja, Monasterio de San Clemente, Monasterio de Santa Inés, etc.), y buena parte de las realizadas en la última década por la Junta de Andalucía. La carencia más significativa es la mayor parte de las rehabilitaciones promovidas por el Ayuntamiento de Sevilla cuyos proyectos no fueron visados ni se dejó copia de los mismos en la Demarcación. Aún con esta salvedad haber localizado información relativa a un 83 \% de
Fig. 2 los edificios inicialmente seleccionados y entre ellos los de mayor singularidad. Así como ofrecer la posibilidad de consultar planos de 65 de ellos supone una importante labor de documentación de utilidad práctica para el conocimiento de los inmuebles seleccionados y las cautelas aplicables a su conservación y uso.

\section{Continuidad y nuevas posibilidades de documentación}

Para 1999 tenemos previsto continuar la colaboración entre FIDAS y el Instituto Andaluz de Patrimonio Histórico a fin de terminar con la segunda fase de trabajo ya iniciado y que consistirá en la informatización de 618 nuevos planos. Así como abrir una nueva línea de trabajo que permita obtener información de las intervenciones realizadas sobre bienes protegidos de otras provincias andaluzas, de los que exista documentación en el Archivo de FIDAS a través de la sección de Archivos Privados Incorporados.

En un futuro próximo se podrían plantear nuevas fases de trabajo que abordasen los inmuebles y conjuntos protegidos de otros municipios de la provincia de Sevilla: Écija, Carmona, Osuna, Marchena, etc.. 


\section{CONYENTO is SANTA MaRIA ILL SOCQRRO}

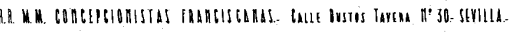

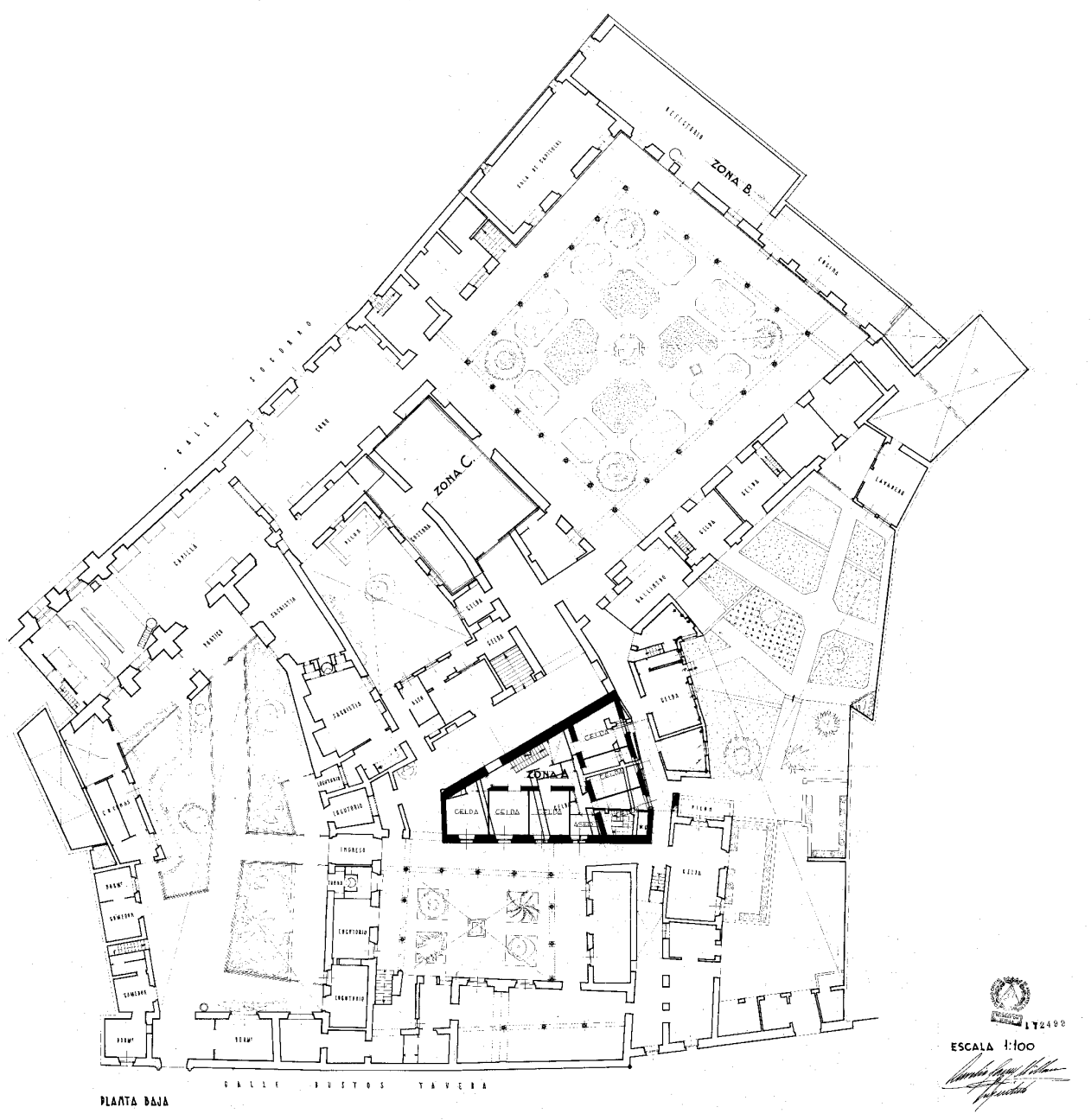

No queremos finalizar este artículo sin señalar que el trabajo que acabamos de exponer ha sido fruto de la colaboración de numerosas personas en ambas instituciones por parte del IAPH los arquitectos responsables del área de documentación de bienes inmuebles Ramón Pico Valimaña y Carlos Tapia Martín supervisaron las diferentes fases de proyecto, aportando ideas para la mejor funcionalidad del resultado final. En FlDAS el trabajo contó con la dirección de los arquitectos Francisco Javier Montero Fernández en un primer momento y posteriormente de Juan Ignacio Santamaría Garrido, en la ejecución, además de los autores de este artículo, debemos citar a José María Fernández de Loaisa y Enrique Vacaro en las tareas de tratamiento informático de los planos y a Carmen Rodríguez Cortasa en los trabajos de documentación.
Fig. 3.

Plano de planta baja del convento de Santa María del Socorro, según el proyecto de reforma de Aurelio Gómez Millán (1963) en el que se puede ver la distribución del edificio antes de las demoliciones de los años 70. 